\title{
DIAGNOSIS AND TREATMENT OF TUMOURS OF THE PANCREAS
}

\author{
By H. J. MCCURRICH, M.S. \\ (Hon. Asst. Surg. and Hon. Gynae. Surg. Royal Sussex County Hospital)
}

These tumours can be divided into:
I. Innocent. (a) Solid adenomata
(b) Cystic: i. True pancreatic cysts
ii. Pseudocysts.

\section{Malignant. Carcinoma.}

I. (a) Adenomata have been described and their removal recorded. They are very rare, and usually discovered accidentally. They have little practical importance.

(b) Cysts. A cyst of the pancreas, whether a true or a pseudocyst, is a comparatively rare condition. Hale White (1) in recording 6,0oo necropsies only found 4 cases of pancreatic cysts. Mahorner and Mattson (2) reported 47 cases of pancreatic cyst occurring in the Mayo Clinic in ten years, and in a later paper reviews the literature, together with the records of the Clinic and operative and necropsy material, 88 cases treated surgically as well as 20 cases found incidentally at necropsy. Of the I08 cases so reviewed only two were true cystadenomata. But the authors state that it is sometimes very hard, or even impossible, to tell whether a cyst is a true cyst or a pseudocyst, as true cysts sometimes lose their epithelial lining.

Pseudocysts result from trauma with the production of a haematoma which later becomes a cyst. Many of the pseudocysts arise in reality from haemorrhages into the lesser sac of the peritoneal cavity.

\section{Diagnosis}

There are no diagnostic symptoms of a pancreatic cyst as such, and there are rarely any signs of pancreatic insufficiency. The patient, as a rule, has some vague discomfort, and a cystic swelling is found in the epigastrium. The cyst may protrude forwards between the liver and the stomach, or between the stomach and the transverse colon, or even below the transverse colon.

In the earlier stages the cyst may be felt as a tumour, and its cystic character masked by the depth at which it lies. Diagnosis will have to be made from a secondary tumour in the liver, or a tumour of the stomach or transverse colon. When the cyst is of a larger size its cystic character will be evident, and the diagnosis will be made from an enlarged gall-bladder (e.g. mucocele) or a cyst of the liver or a mesenteric cyst.

In the case of a pseudocyst, there may be a history of trauma, though this may have occurred several years before, and be difficult to elicit as the patient does not associate the injury with he present complaint. Of the 47 cases in the Mayo Clinic, eight gave a history of previous trauma varying from a few days to six years between the injury and the discovery of the cyst.

A pancreatic cyst is fixed, and does not move with respiration. A barium meal may show deformity of the stomach from an extrinsic cause.

Diagnosis will be made by exclusion of other lesions, if it is made at all. Generally, though its presence may be suspected, the only certain diagnosis is by laparotomy.

\section{Treatment}

Extirpation is not practical as a rule. Marsupialisation and drainage is apt to be followed by a chronic fistula. This may be closed by sclerosing fluids, or it may be implanted into the bowel in the manner described by R. M. Janes (3).

A method that succeeded in the hands of the author of this article in dealing with a fistula leading to a cyst containing about Io oz. of opalescent fluid, which had been previously operated upon elsewhere, was to excise the fistula and bring the cyst as far out of the abdomen as possible. The interior of the cyst was wiped out with pure carbolic, its redundant fundus removed, and the basal portion marsupialised around a tube which was removed after a few days; obliteration of the sac and healing occurred. 


\section{Carcinoma}

\section{Diagnosis}

Carcinoma may occur in any part of the pancreas, but unless it occurs in the head of the gland it does not produce characteristic symptoms. Carcinoma of the body or tail of the gland may not produce any symptoms until secondary deposits appear. Carcinoma of the head of the pancreas produces symptoms mainly as the result of pressure on the common bile duct. The patient becomes jaundiced, and this jaundice is progressive and not intermittent, as in catarrhal jaundice, or jaundice due to a stone. The patient changes from a yellow colour to deeper and deeper tinges, until he becomes a greenish black. Itching due to the jaundice may be intolerable. The patient complains of increasing weakness. The gall-bladder, unless fibrosed by previous disease, becomes enlarged. Courvoisier drew attention to this in what is frequently referred to as his "law" which states that if in a jaundiced patient the gall-bladder is enlarged the cause is not a stone in the common duct, for in such a case previous cholecystitis will have rendered the gall-bladder fibrotic and incapable of expansion.

As a rule, the condition does not produce pain; finally, evidence of lack of pancreatic digestive ferments may occur.

Briefly then, the cardinal signs and symptoms are

$$
\begin{aligned}
& \text { Progressive jaundice, } \\
& \text { Weakness, and an } \\
& \text { Enlarged gall-bladder. }
\end{aligned}
$$

\section{Treatment}

The head of the pancreas has on a few occasions been extirpated, but such treatment is rarely possible, and never likely to become routine.

The routine treatment is palliative, and consists in anastomising the gall-bladder to the stomach or duodenum. Great relief is given to the patient as the bile drains away, the jaundice and dreadful itching disappears, and the patient may live for several months in comfort, with weakness as his only symptom.

Occasionally, chronic pancreatitis may so simulate carcinoma of the head of the pancreas that even at laparotomy it may not be possible to be certain. Some cases diagnosed as carcinoma at the operation have recovered after the anastomising of the gall-bladder to the stomach, and by their subsequent return to health have caused the diagnosis of carcinoma, with its hopeless prognosis, to be revised.

\section{REFERENCES}

(I) HALE WHITE: Guy's Hospital Reports, 1900, liv. 17.

(2) M.A HORNER \& MATTSON: Arch. of Surgery, xxii. p. 1018.

(3) JANES, R. M.: Brit. Journ. of Surgery, xxii. p. 296.

for those who desire to go more deeply into this subject, there is a good bibliography in the article by Mahorner \& Mattson, and the following references may prove useful:-

SETON PRINGLE: Brit. Journ. of Surgery, vol. xiii. p. I80.

E. ROCK CARLING \& J. A. BRAXTON HICKS: Brit. Journ. of Surgery, xiii. p. 238.

A. E. WEBB JOHNSON \& E. G. MUIR: Brit. Journ. of Surgery, xxi. p. 24I. 